\title{
Comparisons on engine power requirements of 6WD and 4WD prime movers for the oil palm plantation in Malaysia
}

\begin{abstract}
An attempt was made to investigate the possibility of designing and developing a multipurpose, all terrain, 6WD prime mover for the oil palm plantation in Malaysia. Comparisons were made on the engine power requirements of the 6WD prime mover over the $4 \mathrm{WD}$ prime mover on four different soil classifications having terrain slopes ranging from 0 to 30 based on the traction equations by ASABE [1]. Generally, the 6WD prime mover showed in the range of $5.27-45.81 \%$ reduction in the engine power requirements than the 4WD prime mover having equal size and weight configurations when traversing over the four different soil classifications. Greater percentage reductions in engine power with the 6WD over the 4WD prime mover were found as the terrain changes from concrete to soft or sandy soil classification with prominent percentage reductions at higher terrain slopes. The proposed 6WD prime mover has a single chassis with skid steer drive wheels, oscillating drive axles, and low inflation pressure tires. The $63 \mathrm{~kW}$ water-cooled, diesel engine was sufficient to run an hydrostatic main pump at a working pressure of 220 bar and a flow rate of $91 \mathrm{~L} / \mathrm{min}$ under two drive speeds (i.e. high and low) and two drive modes (i.e. forward and reverse). Proper prime mover wheelbase and proper ground clearance height were employed to give better stability and manoeuvrability for the typical oil palm plantation terrain in Malaysia. Mounting provisions for the seedling transplanting, fertilizer applicator and the infield fresh fruit bunches (FFB) collection-transportation were made on the prime mover. 2010 ISTVS. Published by Elsevier Ltd. All rights reserved.
\end{abstract}

Keyword: Prime mover, Multi-purpose vehicle, 6WD, 4WD, Vehicle mechanics, engine power requirement 